\title{
Fixed point theorems for some new nonlinear mappings in Hilbert spaces
}

\author{
Lai-Jiu Lin $^{1 *}$, Chih-Sheng Chuang ${ }^{1}$ and Zenn-Tsun Yu ${ }^{2}$
}

\author{
* Correspondence: maljin@cc.ncue. \\ edu.tw \\ 'Department of Mathematics, \\ National Changhua University of \\ Education, Changhua, 50058, \\ Taiwan \\ Full list of author information is \\ available at the end of the article
}

\begin{abstract}
In this paper, we introduced two new classes of nonlinear mappings in Hilbert spaces. These two classes of nonlinear mappings contain some important classes of nonlinear mappings, like nonexpansive mappings and nonspreading mappings. We prove fixed point theorems, ergodic theorems, demiclosed principles, and Ray's type theorem for these nonlinear mappings.

Next, we prove weak convergence theorems for Moudafi's iteration process for these nonlinear mappings. Finally, we give some important examples for these new nonlinear mappings.
\end{abstract}

Keywords: nonspreading mapping, fixed point, demiclosed principle, ergodic theorem, nonexpansive mapping

\section{Introduction}

Let $H$ be a real Hilbert space, and let $C$ be a nonempty closed convex subset of $H$. Then, a mapping $T: C \rightarrow C$ is said to be nonexpansive if $\|T x-T y\| \leq\|x-y\|$ for all $x, y \in C$. The set of fixed points of $T$ is denoted by $F(T)$. The class of nonexpansive mappings is important, and there are many well-known results in the literatures. From literatures, we observe the following fixed point theorems for nonexpansive mappings in Hilbert spaces.

In 1965, Browder [1] gave the following demiclosed principle for nonexpansive mappings in Hilbert spaces.

Theorem 1.1. [1] Let $C$ be a nonempty closed convex subset of a real Hilbert space $H$. Let $T$ be a nonexpansive mapping of $C$ into itself, and let $\left\{x_{n}\right\}$ be a sequence in $C$. If $x_{n} \rightarrow w$ and $\lim _{n \rightarrow \infty}\left\|x_{n}-T x_{n}\right\|=0$, then $T w=w$.

In 1971, Pazy [2] gave the following fixed point theorems for nonexpansive mappings in Hilbert spaces.

Theorem 1.2. [2] Let $H$ be a Hilbert space and let $C$ be a nonempty closed convex subset of $H$. Let $T: C \rightarrow C$ be a nonexpansive mapping. Then, $\left\{T^{n} x\right\}$ is a bounded sequence for some $x \in C$ if and only if $F(T) \neq \varnothing$.

In 1975, Baillon [3] gave the following nonlinear ergodic theorem in a Hilbert space.

Theorem 1.3. [3] Let $C$ be a nonempty closed convex subset of a real Hilbert space $H$, and let $T: C \rightarrow C$ be a nonexpansive mapping. Then, the following conditions are equivalent: 
(i) $F(T) \neq \varnothing$;

(ii) for any $x \in C, S_{n} x:=\frac{1}{n} \sum_{k=0}^{n-1} T^{k} x$ converges weakly to an element of $C$.

In fact, if $F(T) \neq \varnothing$, then $S_{n} x \rightarrow \lim _{n \rightarrow \infty} P T^{n} x$ for each $x \in C$, where $P$ is the metric projection of $H$ onto $F(T)$.

In 1980, Ray [4] gave the following result in a real Hilbert space.

Theorem 1.4. [4] Let $C$ be a nonempty closed convex subset of a real Hilbert space $H$. Then, the following conditions are equivalent.

(i) Every nonexpansive mapping of $C$ into itself has a fixed point in $C$;

(ii) $C$ is bounded.

On the other hand, a mapping $T: C \rightarrow C$ is said to be firmly nonexpansive [5] if

$$
\|T x-T y\|^{2} \leq\langle x-y, T x-T y\rangle
$$

for all $x, y \in C$, and it is an important example of nonexpansive mappings in a Hilbert space.

In 2008, Kohsaka and Takahashi [6] introduced nonspreading mapping and obtained a fixed point theorem for a single nonspreading mapping and a common fixed point theorem for a commutative family of nonspreading mappings in Banach spaces. A mapping $T: C \rightarrow C$ is called nonspreading [6] if

$$
2\|T x-T y\|^{2} \leq\|T x-y\|^{2}+\|T y-x\|^{2}
$$

for all $x, y \in C$. Kohsaka and Takahashi [6] extended Theorem 1.2 for nonspreading mapping in Hilbert spaces. In 2010, Takahashi [7] extended Ray's type theorem for nonspreading mapping in Hilbert spaces. Iemoto and Takahashi [8] also extended the demiclosed principles for nonspreading mappings. Recently, Takahashi and Yao [9] proved the following nonlinear ergodic theorem for nonspreading mappings in Hilbert spaces.

Furthermore, Takahashi and Yao [9] also introduced two nonlinear mappings in Hilbert spaces. A mapping $T: C \rightarrow C$ is called a $T J-1$ mapping [9] if

$$
2\|T x-T y\|^{2} \leq\|x-y\|^{2}+\|T x-y\|^{2}
$$

for all $x, y \in C$. A mapping $T: C \rightarrow C$ is called a TJ-2 [9] mapping if

$$
3\|T x-T y\|^{2} \leq 2\|T x-y\|^{2}+\|T y-x\|^{2}
$$

for all $x, y \in C$. For these two nonlinear mappings, TJ-1 and TJ-2 mappings, Takahashi and Yao [9] also gave similar results to the above theorems.

Motivated by the above works, we introduce two nonlinear mappings in Hilbert spaces.

Definition 1.1. Let $C$ be a nonempty closed convex subset of a Hilbert space $H$. We say $T: C \rightarrow C$ is an asymptotic nonspreading mapping if there exists two functions $\alpha$ : $C \rightarrow[0,2)$ and $\beta: C \rightarrow[0, k], k<2$, such that

$$
\text { (A1) } 2\|T x-T y\|^{2} \leq \alpha(x)\|T x-y\|^{2}+\beta(x)\|T y-x\|^{2} \text { for all } x, y \in C \text {; }
$$


(A2) $0<\alpha(x)+\beta(x) \leq 2$ for all $x \in C$.

Remark 1.1. The class of asymptotic nonspreading mappings contains the class of nonspreading mappings and the class of TJ-2 mappings in a Hilbert space. Indeed, in Definition 1.1, we know that

(i) if $\alpha(x)=\beta(x)=1$ for all $x \in C$, then $T$ is a nonspreading mapping;

(ii) if $\alpha(x)=\frac{4}{3}$ and $\beta(x)=\frac{2}{3}$ for all $x \in C$, then $T$ is a TJ-2 mapping.

Definition 1.2. Let $C$ be a nonempty closed convex subset of a Hilbert space $H$. We say $T: C \rightarrow C$ is an asymptotic $T J$ mapping if there exists two functions $\alpha: C \rightarrow[0$, 2] and $\beta: C \rightarrow[0, k], k<2$, such that

(B1) $2\|T x-T y\|^{2} \leq \alpha(x)\|x-y\|^{2}+\beta(x)\|T x-y\|^{2}$ for all $x, y \in C$;

(B2) $\alpha(x)+\beta(x) \leq 2$ for all $x \in C$.

Remark 1.2. The class of asymptotic TJ mappings contains the class of TJ-1 mappings and the class of nonexpansive mappings in a Hilbert space. Indeed, in Definition 1.2 , we know that

(i) if $\alpha(x)=2$ and $\beta(x)=0$ for each $x \in C$, then $T$ is a nonexpansive mapping;

(ii) if $\alpha(x)=\beta(x)=1$ for each $x \in C$, then $T$ is a $T J-1$ mapping.

On the other hand, the following iteration process is known as Mann's type iteration process [10] which is defined as

$$
x_{n+1}=\alpha_{n} x_{n}+\left(1-\alpha_{n}\right) T x_{n}, \quad n \geq 0,
$$

where the initial guess $x_{0}$ is taken in $C$ arbitrarily and the sequence $\left\{\alpha_{n}\right\}$ is in the interval $[0,1]$.

In 2007, Moudafi [11] studied weak convergence theorems for two nonexpansive mappings $T_{1}, T_{2}$ of $C$ into itself, where $C$ is a closed convex subset of a Hilbert space $H$. They considered the following iterative process:

$$
\left\{\begin{array}{l}
x_{0} \in C \text { chosen arbitrarily } \\
y_{n}=\beta_{n} T_{1} x_{n}+\left(1-\beta_{n}\right) T_{2} x_{n} \\
x_{n+1}=\alpha_{n} x_{n}+\left(1-\alpha_{n}\right) y_{n}
\end{array}\right.
$$

for all $n \in N$, where $\left\{\alpha_{n}\right\}$ and $\left\{\beta_{n}\right\}$ are sequences in $[0,1]$ and $F\left(T_{1}\right) \cap F\left(T_{2}\right) \neq \varnothing$. In 2009, Iemoto and Takahashi [8] also considered this iterative procedure for $T_{1}$ is a nonexpansive mapping and $T_{2}$ is nonspreading mapping of $C$ into itself.

Motivated by the works in $[8,11]$, we also consider this iterative process for asymptotic nonspreading mappings and asymptotic $T J$ mappings.

In this paper, we study asymptotic nonspreading mappings and asymptotic $T J$ mappings. We prove fixed point theorems, ergodic theorems, demiclosed principles, and Ray's type theorem for asymptotic nonspreading mappings and asymptotic TJ mappings. Our results generalize recent results of [1-4,6-9]. Next, we prove weak convergence theorems for Moudafi's iteration process for asymptotic nonspraeding mappings and asymptotic TJ mappings. Finally, we give some important examples for these new nonlinear mappings. 


\section{Preliminaries}

Throughout this paper, let $\mathbb{N}$ be the set of positive integers and let $\mathbb{R}$ be the set of real numbers. Let $H$ be a (real) Hilbert space with inner product $\langle\cdot, \cdot\rangle$ and norm $\|\cdot\|$, respectively. We denote the strongly convergence and the weak convergence of $\left\{x_{n}\right\}$ to $x \in H$ by $x_{n} \rightarrow x$ and $x_{n}-x$, respectively. From [12], for each $x, y \in H$ and $\lambda \in 0$ [1], we have

$$
\|\lambda x+(1-\lambda) y\|^{2}=\lambda\|x\|^{2}+(1-\lambda)\|y\|^{2}-\lambda(1-\lambda)\|x-y\|^{2} .
$$

Let $\ell^{\infty}$ be the Banach space of bounded sequences with the supremum norm. A linear functional $\mu$ on $\ell^{\infty}$ is called a mean if $\mu(e)=\|\mu\|=1$, where $e=(1,1,1, \ldots$.$) . For$ $x=\left(x_{1}, x_{2}, x_{3}, \ldots.\right)$, the value $\mu(x)$ is also denoted by $\mu_{n}\left(x_{n}\right)$. A Banach limit on $\ell^{\infty}$ is an invariant mean, that is, $\mu_{n}\left(x_{n}\right)=\mu_{n}\left(x_{n+1}\right)$. If $\mu$ is a Banach limit on $\ell^{\infty}$, then for $x=\left(x_{1}\right.$, $\left.x_{2}, x_{3}, \ldots\right) \in \ell^{\infty}$,

$$
\liminf _{n \rightarrow \infty} x_{n} \leq \mu_{n} x_{n} \leq \limsup _{n \rightarrow \infty} x_{n}
$$

In particular, if $x=\left(x_{1}, x_{2}, x_{3}, \ldots\right) \in \ell^{\infty}$ and $x_{n} \rightarrow a \in \mathbb{R}$, then we have $\mu(x)=\mu_{n} x_{n}=$ a. For details, we can refer [13].

Let $C$ be a nonempty closed convex subset of a real Hilbert space $H$, and let $T: C \rightarrow$ $C$ be a mapping, and let $F(T)$ denote the set of fixed points of $T$. A mapping $T: C \rightarrow$ $C$ with $F(T) \neq \varnothing$ is called quasi-nonexpansive if $\|x-T y\| \leq\|x-y\|$ for all $x \in F(T)$ and $y \in C$. It is well known that the set $F(T)$ of fixed points of a quasi-nonexpansive mapping $T$ is a closed and convex set [14]. Hence, if $T: C \rightarrow C$ is an asymptotic nonspreading mapping (resp., asymptotic $T J$ mapping) with $F(T) \neq \varnothing$, then $T$ is a quasinonexpansive mapping and this implies that $F(T)$ is a nonempty closed convex subset of $C$.

Proposition 2.1. Let $C$ be a nonempty closed convex subset of a Hilbert space $H$. Let $\alpha, \beta$ be the same as in Definition 1.1. Then, $T: C \rightarrow C$ is an asymptotic nonspreading mapping if and only if

$$
\begin{aligned}
& \|T x-T y\|^{2} \\
& \leq \frac{\alpha(x)-\beta(x)}{2-\beta(x)}\|T x-x\|^{2}+\frac{\alpha(x)\|x-y\|^{2}}{2-\beta(x)}+\frac{2\langle T x-x, \alpha(x)(x-y)+\beta(x)(T y-x)\rangle}{2-\beta(x)}
\end{aligned}
$$

for all $x, y \in C$.

Proof. We have that for $x, y \in C$,

$$
\begin{aligned}
& 2\|T x-T y\|^{2} \\
& \quad \leq \alpha(x)\|T x-y\|^{2}+\beta(x)\|T y-x\|^{2} \\
& \quad=\alpha(x)\|T x-x\|^{2}+2 \alpha(x)\langle T x-x, x-y\rangle+\alpha(x)\|x-y\|^{2} \\
& \quad+\beta(x)\|T y-T x\|^{2}+2 \beta(x)\langle T y-T x, T x-x\rangle+\beta(x)\|T x-x\|^{2} \\
& =(\alpha(x)+\beta(x))\|T x-x\|^{2}+\beta(x)\|T y-T x\|^{2}+\alpha(x)\|x-y\|^{2} \\
& \quad+2 \alpha(x)\langle T x-x, x-y\rangle+2 \beta(x)\langle T y-x+x-T x, T x-x\rangle \\
& =(\alpha(x)-\beta(x))\|T x-x\|^{2}+\beta(x)\|T y-T x\|^{2}+\alpha(x)\|x-y\|^{2} \\
& \quad+\langle T x-x, 2 \alpha(x)(x-y)+2 \beta(x)(T y-x)\rangle .
\end{aligned}
$$


And this implies that

$$
\begin{aligned}
& \|T x-T y\|^{2} \\
& \quad \leq \frac{\alpha(x)-\beta(x)}{2-\beta(x)}\|T x-x\|^{2}+\frac{\alpha(x)\|x-y\|^{2}}{2-\beta(x)}+\frac{2\langle T x-x, \alpha(x)(x-y)+\beta(x)(T y-x)\rangle}{2-\beta(x)} .
\end{aligned}
$$

Hence, the proof is completed.

Remark 2.1. If $\alpha(x)=\beta(x)=1$ for all $x \in C$, then Proposition 2.1 is reduced to Lemma 3.2 in [8].

In the sequel, we need the following lemmas as tools.

Lemma 2.1. [13] Let $C$ be a nonempty closed convex subset of a Hilbert space $H$. Let $P$ be the metric projection from $H$ onto $C$. Then for each $x \in H$, we know that $\langle x$ - Px, $P x-y\rangle \geq 0$ for all $y \in C$.

Lemma 2.2. [15] Let $D$ be a nonempty closed convex subset of a real Hilbert space $H$. Let $P$ be the matric projection of $H$ onto $D$, and let $\left\{x_{n}\right\}_{n \in \mathbb{N}}$ in $H$. If $\left\|x_{n+1}-u\right\| \leq \|$ $x_{n}-u \|$ for all $u \in D$ and $n \in \mathbb{N}$. Then, $\left\{P x_{n}\right\}$ converges strongly to an element of $D$.

Following the similar argument as in the proof of Theorem 3.1.5 [13], we get the following result.

Lemma 2.3. Let $C$ be a nonempty closed convex subset of a real Hilbert space $H$, and let $\mu$ be a Banach limit. Let $\left\{x_{n}\right\}$ be a sequence with $x_{n} \rightarrow w$. If $x \neq w$, then $\mu_{n} \| x_{n}$ $w\left\|<\mu_{n}|| x_{n}-x\right\|$ and $\mu_{n}|| x_{n}-w\left\|^{2}<\mu_{n}|| x_{n}-x\right\|^{2}$.

Lemma 2.4. [9] Let $H$ be a Hilbert space, let $C$ be a nonempty closed convex subset of $H$, and let $T$ be a mapping of $C$ into itself. Suppose that there exists an element $x \in$ $C$ such that $\left\{T^{n} x\right\}$ is bounded and

$$
\mu_{n}\left\|T^{n} x-T y\right\|^{2} \leq \mu_{n}\left\|T^{n} x-y\right\|^{2}, \quad \forall y \in C
$$

for some Banach limit $\mu$. Then, $T$ has a fixed point in $C$.

\section{Main results}

In this section, we study the fixed point theorems, ergodic theorems, demiclosed principles, and Ray's type theorems for asymptotic nonspreading mappings and for asymptotic $T J$ mappings in Hilbert spaces.

\section{1: Fixed point theorems}

Theorem 3.1. Let $C$ be a nonempty closed convex subset of a real Hilbert space $H$, and let $T: C \rightarrow C$ be an asymptotic nonspreading mapping. Then, the following conditions are equivalent.

(i) $\left\{T^{n} x\right\}$ is bounded for some $x \in C$;

(ii) $F(T) \neq \varnothing$.

Proof. In fact, we only need to show that (i) implies (ii). Let $x_{0}=x$. For each $n \in \mathbb{N}$, let $x_{n}:=T x_{n-1}$. Clearly, $\left\{x_{n}\right\}$ is a bounded sequence. Then for each $z \in C$,

$$
\begin{aligned}
\mu_{n}\left\|x_{n}-T z\right\|^{2} & =\mu_{n}\left\|x_{n+1}-T z\right\|^{2} \\
& \leq \mu_{n}\left(\frac{\alpha(z)}{2}\left\|T z-x_{n}\right\|^{2}+\frac{\beta(z)}{2}\left\|T x_{n}-z\right\|^{2}\right) \\
& =\frac{\alpha(z)}{2} \mu_{n}\left\|x_{n}-T z\right\|^{2}+\frac{\beta(z)}{2} \mu_{n}\left\|T x_{n}-z\right\|^{2} \\
& =\frac{\alpha(z)}{2} \mu_{n}\left\|x_{n}-T z\right\|^{2}+\frac{\beta(z)}{2} \mu_{n}\left\|x_{n}-z\right\|^{2} .
\end{aligned}
$$


Hence,

$$
\beta(z) \mu_{n}\left\|x_{n}-T z\right\|^{2} \leq(2-\alpha(z)) \mu_{n}\left\|x_{n}-T z\right\|^{2} \leq \beta(z) \mu_{n}\left\|x_{n}-z\right\|^{2},
$$

and this implies that $\mu_{n}\left\|x_{n}-T z\right\|^{2} \leq \mu_{n}|| x_{n}-z \|^{2}$. By Lemma 2.4, $F(T) \neq \varnothing$. $\square$

Since the class of asymptotic nonspreading mappings contains the class of nonspreading mappings, we get the following result by Theorem 3.1.

Corollary 3.1. [6] Let $H$ be a Hilbert space and let $C$ be a nonempty closed convex subset of $H$. Let $T: C \rightarrow C$ be a nonspreading mapping. Then, $\left\{T^{n} x\right\}$ is bounded for some $x \in C$ if and only if $F(T) \neq \varnothing$.

Theorem 3.2. Let $C$ be a nonempty closed convex subset of a real Hilbert space $H$, and let $T: C \rightarrow C$ be an asymptotic $T J$ mapping. Then, the following conditions are equivalent.

(i) $\left\{T^{n} x\right\}$ is bounded for some $x \in C$;

(ii) $F(T) \neq \varnothing$.

Proof. In fact, we only need to show that (i) implies (ii). Let $x_{0}=x$. For each $n \in \mathbb{N}$, let $x_{n}:=T x_{n-1}$. Clearly, $\left\{x_{n}\right\}$ is a bounded sequence. Then for each $z \in C$,

$$
\begin{aligned}
\mu_{n}\left\|x_{n}-T z\right\|^{2} & =\mu_{n}\left\|T x_{n}-T z\right\|^{2} \\
& \leq \mu_{n}\left(\frac{\alpha(z)}{2}\left\|x_{n}-z\right\|^{2}+\frac{\beta(z)}{2}\left\|T z-x_{n}\right\|^{2}\right) \\
& \leq \frac{\alpha(z)}{2} \mu_{n}\left\|x_{n}-z\right\|^{2}+\frac{\beta(z)}{2} \mu_{n}\left\|x_{n}-T z\right\|^{2} .
\end{aligned}
$$

And this implies that

$$
\frac{\alpha(z)}{2} \mu_{n}\left\|x_{n}-T z\right\|^{2} \leq\left(1-\frac{\beta(z)}{2}\right) \mu_{n}\left\|x_{n}-T z\right\|^{2} \leq \frac{\alpha(z)}{2} \mu_{n}\left\|x_{n}-z\right\|^{2} .
$$

Hence $\mu_{n}\left\|x_{n}-T z\right\|^{2} \leq \mu_{n}\left\|x_{n}-z\right\|^{2}$. By Lemma 2.4, $F(T) \neq \varnothing$. .

Theorem 3.2 generalizes Theorem 1.2 since the class of asymptotic TJ mappings contains the class of nonexpansive mappings. By Theorems 3.1 and 3.2, we also get the following result as special cases, respectively.

Corollary 3.2. [9] Let $H$ be a Hilbert space and let $C$ be a nonempty closed convex subset of $H$. Let $T: C \rightarrow C$ be a $T J-2$ mapping, i.e., $3\|T x-T y\|^{2} \leq 2\|T x-y\|^{2}+\| T y$ $-x \|^{2}$ for all $x, y \in C$. Then, $\left\{T^{n} x\right\}$ is bounded for some $x \in C$ if and only if $F(T) \neq \varnothing$.

Corollary 3.3. [9] Let $H$ be a Hilbert space and let $C$ be a nonempty closed convex subset of $H$. Let $T: C \rightarrow C$ be a TJ-1 mapping, i.e., $2\|T x-T y\|^{2} \leq\|x-y\|^{2}+\| T x-$ $y \|^{2}$ for all $x, y \in C$. Then, $\left\{T^{n} x\right\}$ is bounded for some $x \in C$ if and only if $F(T) \neq \varnothing$.

Theorem 3.3. Let $C$ be a bounded closed convex subset of a real Hilbert space $H$, and let $T: C \rightarrow C$ be an asymptotic nonspreading mapping (respectively, asymptotic TJ mapping). Then, $F(T) \neq \varnothing$.

By Theorem 3.3, we also get the following well-known result.

Corollary 3.4. Let $C$ be a nonempty bounded closed convex subset of a real Hilbert space $H$, and let $T: C \rightarrow C$ be a nonexpansive mapping. Then, $F(T) \neq \varnothing$. 


\section{2: Demiclosed principles}

Lemma 3.1. Let $C$ be a nonempty closed convex subset of a real Hilbert space $H$, and let $T: C \rightarrow C$ be a mapping. Let $\left\{x_{n}\right\}$ be a bounded sequence in $C$ with $\lim _{n \rightarrow \infty}\left\|x_{n}-T x_{n}\right\|=0$. Then, $\mu_{n}\left\|x_{n}-x\right\|^{2}=\mu_{n}\left\|T x_{n}-x\right\|^{2}$ for each $x \in C$.

Proof. Since $\left\{x_{n}\right\}$ is bounded and $\lim _{n \rightarrow \infty}\left\|x_{n}-T x_{n}\right\|=0,\left\{T x_{n}\right\}$ is also a bounded sequence. For each $x \in C$ and $n \in \mathbb{N}$, we know that

$$
\left|\left\langle T x_{n}-x_{n}, x_{n}-x\right\rangle\right| \leq\left\|T x_{n}-x_{n}\right\| \cdot\left\|x_{n}-x\right\| .
$$

Since $\left\{x_{n}\right\}$ is bounded and $\lim _{n \rightarrow \infty}\left\|x_{n}-T x_{n}\right\|=0$, we get $\lim _{n \rightarrow \infty}\left\langle T x_{n}-x_{n}, x_{n}-x\right\rangle=0$. Hence, for each $x \in C$, we know that

$$
\left\|T x_{n}-x\right\|^{2}=\left\|T x_{n}-x_{n}\right\|^{2}+2\left\langle T x_{n}-x_{n}, x_{n}-x\right\rangle+\left\|x_{n}-x\right\|^{2} .
$$

And this implies that $\mu_{n}\left\|T x_{n}-x\right\|^{2}=\mu_{n}\left\|x_{n}-x\right\|^{2}$ for each $x \in C$. $\square$

Theorem 3.4. Let $C$ be a nonempty closed convex subset of a real Hilbert space $H$, and let $T: C \rightarrow C$ be an asymptotic nonspreading mapping. Let $\left\{x_{n}\right\}$ be a sequence in $C$ with $\lim _{n \rightarrow \infty}\left\|x_{n}-T x_{n}\right\|=0$ and $x_{n} \rightarrow w \in C$. Then, $T w=w$.

Proof. Let $\phi: X \rightarrow[0, \infty)$ be defined by

$$
\varphi(x):=\mu_{n}|| x_{n}-x \|^{2}
$$

for each $x \in C$. Since $x_{n} \rightarrow w,\left\{x_{n}\right\}$ is a bounded sequence. Clearly, $\left\{T x_{n}\right\}$ is a bounded sequence. By Lemma 3.1,

$$
\mu_{n}\left\|x_{n}-x\right\|^{2}=\mu_{n}\left\|T x_{n}-x\right\|^{2} \text { for each } x \in C .
$$

Next, we want to show that $T w=w$. If not, then $T w \neq w$. By Lemma 2.3, $0 \leq \phi(w)$ $<\phi(T w)$, and

$$
\begin{aligned}
\mu_{n}\left\|x_{n}-T w\right\|^{2} & =\mu_{n}\left\|T x_{n}-T w\right\|^{2} \\
& \leq \mu_{n}\left(\frac{\alpha(w)}{2}\left\|T w-x_{n}\right\|^{2}+\frac{\beta(w)}{2}\left\|T x_{n}-w\right\|^{2}\right) \\
& =\frac{\alpha(w)}{2} \mu_{n}\left\|x_{n}-T w\right\|^{2}+\frac{\beta(w)}{2} \mu_{n}\left\|T x_{n}-w\right\|^{2} .
\end{aligned}
$$

Hence,

$$
\beta(w) \varphi(T w) \leq(2-\alpha(w)) \varphi(T w) \leq \beta(w) \varphi(w) .
$$

If $\beta(w)>0$, then $\phi(T w) \leq \phi(w)$. And this leads to a contradiction. If $\beta(w)=0$, then $\phi(T w)=0$. This leads to a contradiction. Therefore, $T w=w$. $\square$

Theorem 3.5. Let $C$ be a nonempty closed convex subset of a real Hilbert space $H$, and let $T: C \rightarrow C$ be an asymptotic $T J$ mapping. Let $\left\{x_{n}\right\}$ be a sequence in $C$ with $\lim _{n \rightarrow \infty}\left\|x_{n}-T x_{n}\right\|=0$ and $x_{n} \rightarrow w \in C$. Then, $T w=w$.

Proof. Let $\phi: X \rightarrow[0, \infty)$ be defined by

$$
\varphi(x):=\mu_{n}|| x_{n}-x \|^{2}
$$

for each $x \in C$. Since $x_{n} \rightarrow w,\left\{x_{n}\right\}$ is a bounded sequence. Clearly, $\left\{T x_{n}\right\}$ is a bounded sequence. By Lemma 3.1, 


$$
\mu_{n}\left\|x_{n}-x\right\|^{2}=\mu_{n}\left\|T x_{n}-x\right\|^{2} \text { for each } x \in C .
$$

Next, we want to show that $T w=w$. If not, then $0 \leq \phi(w)<\phi(T w)$. Hence,

$$
\begin{aligned}
\mu_{n}|| x_{n}-T w \|^{2} & =\mu_{n}\left\|T x_{n}-T w\right\|^{2} \\
& \leq \mu_{n}\left(\frac{\alpha(w)}{2}\left\|x_{n}-w\right\|^{2}+\frac{\beta(w)}{2}\left\|T w-x_{n}\right\|^{2}\right) \\
& \leq \frac{\alpha(w)}{2} \mu_{n}\left\|x_{n}-w\right\|^{2}+\frac{\beta(w)}{2} \mu_{n}\left\|x_{n}-T w\right\|^{2} .
\end{aligned}
$$

And this implies that

$$
\left(1-\frac{\beta(w)}{2}\right) \mu_{n}\left\|x_{n}-T w\right\|^{2} \leq \frac{\alpha(w)}{2} \mu_{n}\left\|x_{n}-w\right\|^{2} .
$$

So, $\mu_{n}\left\|x_{n}-T w\right\|^{2} \leq \mu_{n}|| x_{n}-w\left\|^{2} \leq \mu_{n}|| x_{n}-T w\right\|^{2}$. And this leads to a contradiction. Therefore, $T w=w$. $\square$

Theorem 3.5 generalizes Theorem 1.1 since the class of asymptotic $T J$ mappings contains the class of nonexpansive mappings. Furthermore, we have the following results as special cases of Theorems 3.4 and 3.5, respectively.

Corollary 3.5. [8] Let $C$ be a nonempty closed convex subset of a real Hilbert space $H$. Let $T$ be a nonspreading mapping of $C$ into itself, and let $\left\{x_{n}\right\}$ be a sequence in $C$. If $x_{n} \rightarrow w$ and $\lim _{n \rightarrow \infty}\left\|x_{n}-T x_{n}\right\|=0$, then $T w=w$.

Corollary 3.6. [9] Let $C$ be a nonempty closed convex subset of a real Hilbert space $H$. Let $T$ be a TJ-1 mapping of $C$ into itself, and let $\left\{x_{n}\right\}$ be a sequence in $C$. If $x_{n} \rightarrow w$ and $\lim _{n \rightarrow \infty}\left\|x_{n}-T x_{n}\right\|=0$, then $T w=w$.

\section{3: Ergodic theorems}

Theorem 3.6. Let $C$ be a nonempty closed convex subset of a real Hilbert space $H$, and let $T: C \rightarrow C$ be an asymptotic nonspreading mapping. Let $\alpha$ and $\beta$ be the same as in Definition 1.1. Suppose that $\alpha(x) / \beta(x)=r>0$ for all $x \in C$. Then, the following conditions are equivalent.

(i) $F(T) \neq \varnothing$;

(ii) for any $x \in C, S_{n} x=\frac{1}{n} \sum_{k=0}^{n-1} T^{k} x$ converges weakly to an element in $C$.

In fact, if $F(T) \neq \varnothing$, then $S_{n} x \rightarrow \lim _{n \rightarrow \infty} P T^{n} x$ for each $x \in C$, where $P$ is the metric projection of $H$ onto $F(T)$.

Proof. (ii)) $\Rightarrow$ (i): Take any $x \in C$ and let $x$ be fixed. Then, $S_{n} x \rightarrow v$ for some $v \in C$. Then, $v \in F(T)$. Indeed, for any $y \in C$ and $k \in \mathbb{N}$, we have

$$
\begin{aligned}
0 \leq & \alpha\left(T^{k-1} x\right)\left\|T^{k} x-y\right\|^{2}+\beta\left(T^{k-1} x\right)\left\|T y-T^{k-1} x\right\|^{2}-2\left\|T^{k} x-T y\right\|^{2} \\
\leq & \alpha\left(T^{k-1} x\right)\left\{\left\|T^{k} x-T y\right\|^{2}+2\left\langle T^{k} x-T y, T y-y\right\rangle+\|T y-y\|^{2}\right\} \\
& +\beta\left(T^{k-1} x\right)\left\|T y-T^{k-1} x\right\|^{2}-\left(\alpha\left(T^{k-1} x\right)+\beta\left(T^{k-1} x\right)\right)\left\|T^{k} x-T y\right\|^{2} \\
= & \beta\left(T^{k-1} x\right)\left(\left\|T y-T^{k-1} x\right\|^{2}-\left\|T^{k} x-T y\right\|^{2}\right)+2 \alpha\left(T^{k-1} x\right)\left\langle T^{k} x-T y, T y-y\right\rangle \\
& +\alpha\left(T^{k-1} x\right)\|T y-y\|^{2} .
\end{aligned}
$$


Hence,

$$
\left\|T^{k} x-T y\right\|^{2}-\left\|T^{k-1} x-T y\right\|^{2} \leq 2 r\left\langle T^{k} x-T y, T y-y\right\rangle+r\|T y-y\|^{2} .
$$

Summing up these inequalities with respect to $k=1,2, \ldots, n-1$,

$$
\begin{aligned}
- & \|x-T y\|^{2} \\
& \leq\left\|T^{n-1} x-T y\right\|^{2}-\|x-T y\|^{2} \\
& \leq(n-1) r\|T y-y\|^{2}+2 r\left\langle\left(\sum_{k=1}^{n-1} T^{k} x\right)-(n-1) T y, T y-y\right\rangle \\
& =(n-1) r\|T y-y\|^{2}+2 r\left\langle n S_{n} x-x-(n-1) T y, T y-y\right\rangle .
\end{aligned}
$$

Dividing this inequality by $n$, we have

$$
\frac{-\|x-T y\|^{2}}{n} \leq r\|T y-y\|^{2}+2 r y\left\langle S_{n} x-\frac{x}{n}-\frac{(n-1) T y}{n}, T y-y\right\rangle \text {. }
$$

Letting $n \rightarrow \infty$, we obtain

$$
0 \leq r\|T y-y\|^{2}+2 r\langle v-T y, T y-y\rangle \text {. }
$$

Since $y$ is any point of $C$ and $r>0$, let $y=v$ and this implies that $T v=v$.

(i) $\Rightarrow$ (ii): Take any $x \in C$ and $u \in F(T)$, and let $x$ and $u$ be fixed. Since $T$ is an asymptotic nonspreading mapping, $\left\|T^{n} x-u\right\| \leq\left\|T^{n-1} x-u\right\|$ for each $n \in \mathbb{N}$. By Lemma 2.2, $\left\{P T^{n} x\right\}$ converges strongly to an element $p$ in $F(T)$. Then for each $n \in \mathbb{N}$,

$$
\left\|S_{n} x-u\right\| \leq \frac{1}{n} \sum_{k=0}^{n-1}\left\|T^{k} x-u\right\| \leq\|x-u\| .
$$

So, $\left\{S_{n} x\right\}$ is a bounded sequence. Hence, there exists a subsequence $\left\{S_{n_{i}} x\right\}$ of $\left\{S_{n} x\right\}$ and $v \in C$ such that $S_{n_{i}} x \rightarrow v$. As the above proof, $T v=v$.

By Lemma 2.1, for each $k \in \mathbb{N},\left\langle T^{k} x-P T^{k} x, P T^{k} x-u\right\rangle \geq 0$. And this implies that

$$
\begin{aligned}
\left\langle T^{k} x-P T^{k} x, u-p\right\rangle & \leq\left\langle T^{k} x-P T^{k} x, P T^{k} x-p\right\rangle \\
& \leq\left\|T^{k} x-P T^{k} x\right\| \cdot\left\|P T^{k} x-p\right\| \\
& \leq\left\|T^{k} x-p\right\| \cdot\left\|P T^{k} x-p\right\| \\
& \leq\|x-p\| \cdot\left\|P T^{k} x-p\right\| .
\end{aligned}
$$

Adding these inequalities from $k=0$ to $k=n-1$ and dividing $n$, we have

$$
\left\langle S_{n} x-\frac{1}{n} \sum_{k=0}^{n-1} P T^{k} x, u-p\right\rangle \leq \frac{\|x-p\|}{n} \sum_{k=0}^{n-1}\left\|P T^{k} x-p\right\| .
$$

Since $S_{n_{i}} x \rightarrow v$ and $P T^{k} x \rightarrow p$, we get $\langle v-p, u-p\rangle \leq 0$. Since $u$ is any point of $F(T)$, we know that $v=p$.

Furthermore, if $\left\{S_{n_{j}} x\right\}$ is a subsequence of $\left\{S_{n} x\right\}$ and $S_{n_{j}} \rightarrow w$, then $w=p$ by following the same argument as in the above proof. Therefore, $S_{n} x \rightarrow p=\lim _{n \rightarrow \infty} P T^{n} x$, and the proof is completed.

Theorem 3.7. Let $C$ be a nonempty closed convex subset of a real Hilbert space $H$, and let $T: C \rightarrow C$ be an asymptotic $T J$ mapping. Let $\alpha$ and $\beta$ be the same as in 
Definition 1.2. Suppose that $\beta(x) / \alpha(x)=r>0$ for all $x \in C$. Then, the following conditions are equivalent.

(i) $F(T) \neq \varnothing$;

(ii) for any $x \in C, S_{n} x=\frac{1}{n} \sum_{k=0}^{n-1} T^{k} x$ converges weakly to an element in $C$.

In fact, if $F(T) \neq \varnothing$, then $S_{n} x \rightarrow \lim _{n \rightarrow \infty} P T^{n} x$ for each $x \in C$, where $P$ is the metric projection of $H$ onto $F(T)$.

Proof. The proof of Theorem 3.7 is similar to the proof of Theorem 3.6, and we only need to show the following result.

Take any $x \in C$ and let $x$ be fixed. Then, $S_{n} x \rightarrow v$ for some $v \in C$. Then, $v \in F(T)$. Indeed, for any $y \in C$ and $k \in \mathbb{N}$, we have

$$
\begin{aligned}
0 \leq & \alpha\left(T^{k-1} x\right)\left\|T^{k-1} x-y\right\|^{2}+\beta\left(T^{k-1} x\right)\left\|T^{k} x-y\right\|^{2}-2\left\|T^{k} x-T y\right\|^{2} \\
= & \alpha\left(T^{k-1} x\right)\left\|T^{k-1} x-y\right\|^{2}+\beta\left(T^{k-1} x\right)\left\|T^{k} x-T y\right\|^{2}+2 \beta\left(T^{k-1} x\right)\left\langle T^{k} x-T y, T y-y\right\rangle \\
& +\beta\left(T^{k-1} x\right)\|T y-y\|^{2}-2\left\|T^{k} x-T y\right\|^{2} \\
\leq & \alpha\left(T^{k-1} x\right)\left(\left\|T^{k-1} x-y\right\|^{2}-\left\|T^{k} x-T y\right\|^{2}\right)+2 \beta\left(T^{k-1} x\right)\left\langle T^{k} x-T y, T y-y\right\rangle \\
& +\beta\left(T^{k-1} x\right)\|T y-y\|^{2} .
\end{aligned}
$$

And this implies that

$$
\left\|T^{k} x-T y\right\|^{2}-\left\|T^{k-1} x-T y\right\|^{2} \leq 2 r\left\langle T^{k} x-T y, T y-y\right\rangle+r\|T y-y\|^{2} .
$$

And following the same argument as the proof of Theorem 3.6, we get Theorem 3.7.

By Theorems 3.6 and 3.7, we get the following result.

Corollary 3.7. $[9,16]$ Let $C$ be a nonempty closed convex subset of a real Hilbert space $H$, and let $T: C \rightarrow C$ be any one of nonspreading mapping, TJ-1 mapping, and TJ-2 mapping. Then, the following conditions are equivalent.

(i) $F(T) \neq \varnothing$;

(ii) for any $x \in C, S_{n} x=\frac{1}{n} \sum_{k=0}^{n-1} T^{k} x$ converges weakly to an element in $C$.

In fact, if $F(T) \neq \varnothing$, then $S_{n} x \rightarrow \lim _{n \rightarrow \infty} P T^{n} x$ for each $x \in C$, where $P$ is the metric projection of $H$ onto $F(T)$.

\subsection{Ray's type theorems}

Theorem 3.8. Let $C$ be a nonempty closed convex subset of a real Hilbert space $H$. Then, the following conditions are equivalent.

(i) Every asymptotic $T J$ mapping of $C$ into itself has a fixed point in $C$;

(ii) $C$ is bounded.

Proof. (i) $\Rightarrow$ (ii): Suppose that every asymptotic $T J$ mapping of $C$ into itself has a fixed point in $C$. Since the class of asymptotic $T J$ mappings contains the class of 
nonexpansive mappings, every nonexpansive mapping of $C$ into itself has a fixed point in $C$. By Theorem 1.4, $C$ is bounded. Conversely, by Theorem 3.3, it is easy to show that (ii) $\Rightarrow$ (i).

By Theorem 4.9 in [7] and Theorem 3.3, we get the following result.

Theorem 3.9. Let $C$ be a nonempty closed convex subset of a real Hilbert space $H$. Then, $C$ is bounded if and only if every asymptotic nonspreading mapping of $C$ into itself has a fixed point in $C$.

\subsection{Common fixed point theorems}

Following the similar argument as the proof of Lemma 4.5 in [6], we get the following results. For details, we give the proof of Theorem 3.10.

Theorem 3.10. Let $C$ be a nonempty bounded closed convex subset of a real Hilbert space $H$, and let $\left\{T_{1}, T_{2}, \ldots ., T_{N}\right\}$ be a commutative finite family of asymptotic nonspreading mappings from $C$ into itself. Then, $\left\{T_{1}, T_{2}, \ldots ., T_{N}\right\}$ has a common fixed point.

Proof. The proof is given by induction with respect to $N$. We first show the case that $N=2$. By Theorem 3.3, $F\left(T_{1}\right) \neq \varnothing$ and $F\left(T_{2}\right) \neq \varnothing$. Furthermore, $F\left(T_{1}\right)$ and $F\left(T_{2}\right)$ are bounded closed convex subsets of $C$. Furthermore, $T_{2}\left(F\left(T_{1}\right)\right) \subseteq F\left(T_{1}\right)$. Indeed, if $u \in F$ $\left(T_{1}\right)$, then $T_{1} T_{2} u=T_{2} T_{1} u=T_{2} u$. Hence, $T_{2} u \in F\left(T_{1}\right)$, and this implies that $T_{2}\left(F\left(T_{1}\right)\right)$ $\subseteq F\left(T_{1}\right)$. Let $T_{2}^{\prime}: F\left(T_{1}\right) \rightarrow F\left(T_{1}\right)$ be defined by $T_{2}^{\prime}(x):=T_{2}(x)$ for each $x \in F\left(T_{1}\right)$. Clearly, $T_{2}^{\prime}: F\left(T_{1}\right) \rightarrow F\left(T_{1}\right)$ is a asymptotic nonspreading mapping. By Theorem 3.3 again, there exists $\bar{x} \in F\left(T_{1}\right)$ such that $\bar{x}=T_{2}^{\prime}(\bar{x})=T_{2}(\bar{x})$. So, $\bar{x} \in F\left(T_{1}\right) \cap F\left(T_{2}\right)$.

Suppose that for some $n \geq 2, X=\cap_{k=1}^{n} F\left(T_{k}\right) \neq \emptyset$. Then, $X$ is a nonempty bounded closed convex subset of $C$. Let $T_{n+1}^{\prime}: X \rightarrow$ Xbe defined by $T_{n+1}^{\prime}(x)=T_{n+1}(x)$ for each $x$ $\in X$. Clearly, $T_{n+1}^{\prime}$ is an asymptotic nonspreading mapping. By Theorem 3.3 again, we know that $X \cap F\left(T_{n+1}\right) \neq \varnothing$. That is, $\cap_{k=1}^{n+1} F\left(T_{k}\right) \neq \emptyset$. And the proof is completed.

Corollary 3.8. [6] Let $C$ be a nonempty bounded closed convex subset of a real Hilbert space $H$, and let $\left\{T_{1}, T_{2}, \ldots ., T_{N}\right\}$ be a commutative finite family of non-spreading mappings from $C$ into itself. Then, $\left\{T_{1}, T_{2}, \ldots ., T_{N}\right\}$ has a common fixed point.

Theorem 3.11. Let $C$ be a nonempty bounded closed convex subset of a real Hilbert space $H$, and let $\left\{T_{1}, T_{2}, \ldots, T_{N}\right\}$ be a commutative finite family of asymptotic $T J$ mappings from $C$ into itself. Then, $\left\{T_{1}, T_{2}, \ldots ., T_{N}\right\}$ has a common fixed point.

\section{Weak convergence theorem for common fixed point}

Theorem 4.1. Let $C$ be a nonempty closed convex subset of a real Hilbert space $H$, and let $T_{i}: C \rightarrow C, i=1,2$, be any one of asymptotic nonspreading mapping and asymptotic $T J$ mapping. Let $\mathfrak{I}=F\left(T_{1}\right) \cap F\left(T_{2}\right) \neq \varnothing$. Let $\left\{a_{n}\right\}$ and $\left\{b_{n}\right\}$ be two sequences in $(0,1)$. Let $\left\{x_{n}\right\}$ be defined by

$$
\left\{\begin{array}{l}
x_{1} \in C \text { chosen arbitrary, } \\
x_{n+1}:=a_{n} x_{n}+\left(1-a_{n}\right)\left(b_{n} T_{1} x_{n}+\left(1-b_{n}\right) T_{2} x_{n}\right) .
\end{array}\right.
$$

Assume that $\liminf _{n \rightarrow \infty} a_{n}\left(1-a_{n}\right)>0$ and $\liminf _{n \rightarrow \infty} b_{n}\left(1-b_{n}\right)>0$. Then, $x_{n} \rightarrow w$ for some $w \in \mathfrak{3}$.

Proof. Take any $w \in \mathfrak{I}$ and let $w$ be fixed. Then for each $n \in \mathbb{N}$, we have $\left\|T_{i} x_{n}-w\right\|$ $\leq\left\|x_{n}-w\right\|$ for each $n \in \mathbb{N}$ and $i=1,2$. Hence, 


$$
\begin{aligned}
& \left\|b_{n} T_{1} x_{n}+\left(1-b_{n}\right) T_{2} x_{n}-w\right\|^{2} \\
& \quad=b_{n}\left\|T_{1} x_{n}-w\right\|^{2}+\left(1-b_{n}\right)\left\|T_{2} x_{n}-w\right\|^{2}-b_{n}\left(1-b_{n}\right)\left\|T_{1} x_{n}-T_{2} x_{n}\right\|^{2} \\
& \quad \leq b_{n}\left\|T_{1} x_{n}-w\right\|^{2}+\left(1-b_{n}\right)\left\|T_{2} x_{n}-w\right\|^{2} \\
& \quad \leq\left\|x_{n}-w\right\|^{2}
\end{aligned}
$$

and

$$
\begin{aligned}
& \left\|x_{n+1}-w\right\|^{2} \\
& \quad=\left\|a_{n} x_{n}+\left(1-a_{n}\right)\left(b_{n} T_{1} x_{n}+\left(1-b_{n}\right) T_{2} x_{n}\right)-w\right\|^{2} \\
& \quad \leq a_{n}\left\|x_{n}-w\right\|^{2}+\left(1-a_{n}\right)\left\|b_{n} T_{1} x_{n}+\left(1-b_{n}\right) T_{2} x_{n}-w\right\|^{2} \\
& \quad-a_{n}\left(1-a_{n}\right)\left\|\left(b_{n} T_{1} x_{n}+\left(1-b_{n}\right) T_{2} x_{n}\right)-x_{n}\right\|^{2} \\
& \quad \leq\left(1-a_{n}\right)\left\|x_{n}-w\right\|^{2}+a_{n}\left\|x_{n}-w\right\|^{2}-a_{n}\left(1-a_{n}\right)\left\|\left(b_{n} T_{1} x_{n}+\left(1-b_{n}\right) T_{2} x_{n}\right)-x_{n}\right\|^{2} \\
& \quad=\left\|x_{n}-w\right\|^{2}-a_{n}\left(1-a_{n}\right)\left\|\left(b_{n} T_{1} x_{n}+\left(1-b_{n}\right) T_{2} x_{n}\right)-x_{n}\right\|^{2} .
\end{aligned}
$$

Hence, $\left\{\left\|x_{n}-w\right\|\right\}$ is a nonincreasing sequence, and $\lim _{n \rightarrow \infty}\left\|x_{n}-w\right\|$ exists. Besides, we know that

$$
a_{n}\left(1-a_{n}\right)\left\|\left(b_{n} T_{1} x_{n}+\left(1-b_{n}\right) T_{2} x_{n}\right)-x_{n}\right\|^{2} \leq\left\|x_{n}-w\right\|^{2}-\left\|x_{n+1}-w\right\|^{2} .
$$

And this implies that $\lim _{n \rightarrow \infty}\left\|\left(b_{n} T_{1} x_{n}+\left(1-b_{n}\right) T_{2} x_{n}\right)-x_{n}\right\|=0$. Next, we also have

$$
\begin{aligned}
\left\|x_{n+1}-x_{n}\right\| & =\left\|a_{n} x_{n}+\left(1-a_{n}\right)\left(b_{n} T_{1} x_{n}+\left(1-b_{n}\right) T_{2} x_{n}\right)-x_{n}\right\| \\
& =\left(1-a_{n}\right)\left\|b_{n} T_{1} x_{n}+\left(1-b_{n}\right) T_{2} x_{n}-x_{n}\right\|,
\end{aligned}
$$

and this implies that $\lim _{n \rightarrow \infty}\left\|x_{n+1}-x_{n}\right\|=0$. Besides, we get:

$$
\begin{aligned}
& b_{n}\left(1-b_{n}\right)\left\|T_{1} x_{n}-T_{2} x_{n}\right\|^{2} \\
& \quad \leq\left\|x_{n}-w\right\|^{2}-\left\|b_{n} T_{1} x_{n}+\left(1-b_{n}\right) T_{2} x_{n}-w\right\|^{2} \\
& \quad \leq M\left(\left\|x_{n}-w\right\|-\left\|b_{n} T_{1} x_{n}+\left(1-b_{n}\right) T_{2} x_{n}-w\right\|\right) \\
& \quad \leq M\left\|\left(x_{n}-w\right)-\left(b_{n} T_{1} x_{n}+\left(1-b_{n}\right) T_{2} x_{n}-w\right)\right\| \\
& \quad=M\left\|b_{n} T_{1} x_{n}+\left(1-b_{n}\right) T_{2} x_{n}-x_{n}\right\| .
\end{aligned}
$$

Then $\lim _{n \rightarrow \infty} b_{n}\left(1-b_{n}\right)\left\|T_{1} x_{n}-T_{2} x_{n}\right\|^{2}=0$. Since $\lim _{n \rightarrow \infty} \inf _{n}\left(1-b_{n}\right)>0$, we get $\lim _{n \rightarrow \infty}\left\|T_{1} x_{n}-T_{2} x_{n}\right\|=0$. We have that

$$
\begin{aligned}
& \left\|x_{n+1}-T_{1} x_{n}\right\| \\
& \quad=\left\|a_{n} x_{n}+\left(1-a_{n}\right)\left(b_{n} T_{1} x_{n}+\left(1-b_{n}\right) T_{2} x_{n}\right)-T_{1} x_{n}\right\| \\
& \quad=\left\|a_{n}\left(x_{n}-T_{1} x_{n}\right)+\left(1-a_{n}\right)\left(b_{n} T_{1} x_{n}+\left(1-b_{n}\right) T_{2} x_{n}-T_{1} x_{n}\right)\right\| \\
& \quad=\left\|a_{n}\left(x_{n}-T_{1} x_{n}\right)+\left(1-a_{n}\right)\left(1-b_{n}\right)\left(T_{2} x_{n}-T_{1} x_{n}\right)\right\| \\
& \quad \leq a_{n}\left\|x_{n}-T_{1} x_{n}\right\|+\left(1-a_{n}\right)\left(1-b_{n}\right)\left\|T_{2} x_{n}-T_{1} x_{n}\right\| \\
& \quad \leq a_{n}\left\|x_{n}-x_{n+1}\right\|+a_{n}\left\|x_{n+1}-T_{1} x_{n}\right\|+\left(1-a_{n}\right)\left(1-b_{n}\right)\left\|T_{2} x_{n}-T_{1} x_{n}\right\| .
\end{aligned}
$$

And this implies that

$$
\left(1-a_{n}\right)|| x_{n+1}-T_{1} x_{n}\left\|\leq a_{n}\right\| x_{n}-x_{n+1}\left\|+\left(1-a_{n}\right)\left(1-b_{n}\right)|| T_{2} x_{n}-T_{1} x_{n}\right\| .
$$

Hence,

$$
a_{n}\left(1-a_{n}\right)\left\|x_{n+1}-T_{1} x_{n}\right\| \leq\left\|x_{n}-x_{n+1}\right\|+\left\|T_{2} x_{n}-T_{1} x_{n}\right\| .
$$


So, $\lim _{n \rightarrow \infty} a_{n}\left(1-a_{n}\right)\left\|x_{n+1}-T_{1} x_{n}\right\|=0$. By assumption, $\lim _{n \rightarrow \infty}\left\|x_{n+1}-T_{1} x_{n}\right\|=0$, and this implies that

$$
\lim _{n \rightarrow \infty}\left\|x_{n}-T_{1} x_{n}\right\|=\lim _{n \rightarrow \infty}\left\|x_{n}-T_{2} x_{n}\right\|=0 .
$$

Since $\left\{x_{n}\right\}$ is bounded, there exists a subsequence $\left\{x_{n_{k}}\right\}$ of $\left\{x_{n}\right\}$ such that $x_{n_{k}} \rightarrow w \in C$. By Theorems 3.4 and 3.5, $T_{1} w=T_{2} w=w$.

If $x_{n_{j}}$ is a subsequence of $\left\{x_{n}\right\}$ and $x_{n_{j}} \rightarrow u$, then $T_{1} u=T_{2} u=u$. Suppose that $u \neq w$. Then, we have:

$$
\begin{aligned}
\liminf _{k \rightarrow \infty}\left\|x_{n_{k}}-w\right\| & <\liminf _{k \rightarrow \infty}\left\|x_{n_{k}}-u\right\| \\
& =\lim _{n \rightarrow \infty}\left\|x_{n}-u\right\| \\
& =\lim _{j \rightarrow \infty}\left\|x_{n_{j}}-u\right\| \\
& <\liminf _{j \rightarrow \infty}\left\|x_{n_{j}}-w\right\| \\
& =\lim _{n \rightarrow \infty}\left\|x_{n}-w\right\|=\liminf _{k \rightarrow \infty}\left\|x_{n_{k}}-w\right\| .
\end{aligned}
$$

And this leads to a contradiction. Then, $x_{n} \rightarrow w$, and the proof is completed.

Remark 4.1. Theorem 4.1 generalizes Theorem 4.1 (iii) in [8]. Similarly, the following corollary generalizes Corollary 4.1 in [8].

Corollary 4.1. Let $C$ be a closed convex subset of a real Hilbert space $H$, and let $T$ : $C \rightarrow C$ be any one of asymptotic nonspreading mapping and asymptotic $T J$ mapping. Suppose that $F(T) \neq \varnothing$. Let $\left\{a_{n}\right\}$ be a sequence in $(0,1)$. Let $\left\{x_{n}\right\}$ be defined by

$$
\left\{\begin{array}{l}
x_{1} \in C \text { chosen arbitrary, } \\
x_{n+1}:=\left(1-a_{n}\right) x_{n}+a_{n} T x_{n} .
\end{array}\right.
$$

If $\lim _{n \rightarrow \infty} \inf _{n}\left(1-a_{n}\right)>0$, then $x_{n} \rightarrow w$ for some $w \in F(T)$.

Proof. Let $T_{1}, T_{2}: C \rightarrow C$ be defined by $T_{1} x=T_{2} x=T x$ for each $x \in C$, and let $b_{n}=$ $1 / 2$ for each $n \in \mathbb{N}$. Then, Corollary 4.1 follows from Theorem 4.1.

\section{Examples}

The following example shows that $T$ is an asymptotic nonspreading mapping. But $T$ is not a nonspreading mapping and not a TJ-2 mapping.

Example 5.1. Let $H=\mathbb{R}, C:=[0, \infty)$, and let $T: C \rightarrow C$ be defined by

$$
T(x):=\left\{\begin{array}{l}
0.8 \text { if } 1 \leq x \\
0 \quad \text { if } 0 \leq x<1
\end{array}\right.
$$

for each $x \in \mathbb{R}$. Then, $T$ is not a nonspreading mapping. Indeed, if $x=1.1$ and $y=$ 0.6 , then

$$
2\|T x-T y\|^{2}=1.28>1.25=0.04+1.21=\|T x-y\|^{2}+\|T y-x\|^{2} .
$$

Furthermore, $T$ is not a $T J-2$ mapping. Indeed, if $x=1.1$ and $y=0.6$, then

$$
2\|T x-T y\|^{2}=1.28>0.86=\frac{4}{3} \times 0.04+\frac{2}{3} \times 1.21=\frac{4}{3}\|T x-y\|^{2}+\frac{2}{3}\|T y-x\|^{2} .
$$


However, $T$ is an asymptotic nonspreading mapping. Indeed, let $\alpha: C \rightarrow[0,2)$ and $\beta$ : $C \rightarrow[0,1.9)$ be defined by

$$
\alpha(x):= \begin{cases}0 & \text { if } 1 \leq x \\ 1.28 & \text { if } 0 \leq x<1\end{cases}
$$

and

$$
\beta(x):= \begin{cases}1.28 & \text { if } 1 \leq x \\ 0 & \text { if } 0 \leq x<1\end{cases}
$$

Now, we only need to consider the following two cases.

(a) If $x \geq 1$ and $0 \leq y<1$, then $\alpha(x)=0, \beta(x)=1.28$, and

$$
2\|T x-T y\|^{2}=1.28 \leq \beta(x) \cdot x^{2}=\alpha(x)\|T x-y\|^{2}+\beta(x)\|T y-x\|^{2} .
$$

(b) If $0 \leq x<1$ and $y \geq 1$, then $\alpha(x)=1.28, \beta(x)=0$, and

$$
2\|T x-T y\|^{2}=1.28 \leq \alpha(x) \cdot y^{2}=\alpha(x)\|T x-y\|^{2}+\beta(x)\|T y-x\|^{2} .
$$

Therefore, $T$ is an asymptotic nonspreading mapping. $\square$

Remark 5.1. Example 5.1 can be applied to demonstrate Theorems 3.1, 3.3, 3.4, and Corollary 4.1.

The following example shows that $T$ is an asymptotic $\mathrm{TJ}$ mapping, but $T$ is not a nonexpansive mapping.

Example 5.2. Let $H=\mathbb{R}, C:=[0,3]$, and let $T: C \rightarrow C$ be defined by

$$
T(x):=\left\{\begin{array}{l}
0 \text { if } x \neq 3 \\
1 \text { if } x=3,
\end{array}\right.
$$

for each $x \in \mathbb{R}$. Then $T$ is not a nonexpansive: mapping. Indeed, if $x=3$ and $y=2.9$, then

$$
\|T x-T y\|^{2}=1>0.01=\|x-y\|^{2} .
$$

However, $T$ is an asymptotic $T J$ mapping. Indeed, let $\alpha: C \rightarrow[0,2)$ and $\beta: C \rightarrow[0$, 1.9) be defined by

$$
\alpha(x):=\left\{\begin{array}{l}
0 \text { if } x \neq 3 \\
1 \text { if } x=3
\end{array}\right.
$$

and

$$
\beta(x):=\left\{\begin{array}{l}
\frac{1}{3} \text { if } x \neq 3 \\
1 \text { if } x=3
\end{array}\right.
$$

Now, we only need to consider the following two cases.

(a) If $x \neq 3$ and $y=3$, then $\alpha(x)=0, \beta(x)=\frac{1}{3}$, and

$$
2\|T x-T y\|^{2}=2<3=\frac{1}{3} \times 9=\alpha(x)\|x-y\|^{2}+\beta(x)\|T x-y\|^{2} .
$$


(b) If $x=3$ and $y \neq 3$, then $\alpha(x)=1, \beta(x)=1$, and

$$
\begin{aligned}
\alpha(x)\|x-y\|^{2}+\beta(x)\|T x-y\|^{2} & =(3-y)^{2}+(1-y)^{2} \\
& =\left(y^{2}-6 y+9\right)+\left(y^{2}-2 y+1\right) \\
& =2(y-2)^{2}+2 \\
& \geq 2\|T x-T y\|^{2} .
\end{aligned}
$$

Therefore, $T$ is an asymptotic $T J$ mapping. Note that $T$ is a $T J-1$ mapping. $\square$

Remark 5.2. Example 5.2 can be applied to demonstrate Theorems 3.2, 3.3, 3.5, and Corollary 4.1. Furthermore, Examples 5.1 and 5.2 can also be applied to demonstrate Theorem 4.1.

\section{Competing interests}

The authors declare no competing interests, except Prof. L. J. Lin was supported by the National Science Council of Republic of China while he work on the publish, and C. S. Chuang was support as postdoctor by the National Science Council of the Republic of China while he worked on this problem.

\section{Authors' contributions}

LJL: Problem resign, coordinator, discussion, revise the important part, and submit CSC: Responsible for the important results of asymptotic nonspreading mappings and asymptotic TJ mapping, discuss, draft. ZTY: responsible for giving the examples of this types of problems, discussion.

\section{Author details}

${ }^{1}$ Department of Mathematics, National Changhua University of Education, Changhua, 50058, Taiwan ${ }^{2}$ Department of Electronic Engineering, Nan Kai University of Technology, Nantour, 542, Taiwan

Received: 19 January 2011 Accepted: 13 September 2011 Published: 13 September 2011

References

1. Browder, FE: Fifixed point theorems for noncompact mappings in Hilbert spaces. Proc Nat Acad Sci USA. 53, 1272-1276 (1965). doi:10.1073/pnas.53.6.1272

2. Pazy, A: Asymptotic behavior of contractions in Hilbert space. Israel J Math. 9, 235-240 (1971). doi:10.1007/BF02771588

3. Baillon, JB: Un theoreme de type ergodique pour les contractions non lineaires dans un espace de Hilbert. C. R. Acad Sci Paris Ser A-B. 280, 1511-1514 (1975)

4. Ray, WO: The fixed point property and unbounded sets in Hilbert space. Trans Amer Math Soc. 258, $531-537$ (1980). doi:10.1090/S0002-9947-1980-0558189-1

5. Goebel, K, Kirk, WA: Topics in Metric Fixed Point Theory. Cambridge University Press, Cambridge (1990)

6. Kohsaka, F, Takahashi, W: Fixed point theorems for a class of nonlinear mappings related to maximal monotone operators in Banach spaces. Arch Math. 91, 166-177 (2008). doi:10.1007/s00013-008-2545-8

7. Takahashi, W: Nonlinear mappings in equilibrium problems and an open problem in fixed point theory. Proceedings of the Ninth International Conference on Fixed Point Theory and Its Applications. pp. 177-197.Yokohama Publishers (2010)

8. lemoto, S, Takahashi, W: Approximating common fixed points of nonexpansive mappings and nonspreading mappings in a Hilbert space. Nonlinear Anal. 71, e2082-e2089 (2009). doi:10.1016/j.na.2009.03.064

9. Takahashi, W, Yao, JC: Fixed point theorems and ergodic theorems for non-linear mappings in Hilbert spaces. Taiwan J Math. 15, 457-472 (2011)

10. Mann, WR: Mean value methods in iteration. Proc Amer Math Soc. 4, 506-510 (1953). doi:10.1090/S0002-9939-19530054846-3

11. Moudafi, A: Krasnoselski-Mann iteration for hierarchical fixed-point problems. Inverse Probl. 23, 1635-1640 (2007). doi:10.1088/0266-5611/23/4/015

12. Takahashi, W: Introduction to Nonlinear and Convex Analysis. Yokohoma Publishers, Yokohoma (2009)

13. Takahashi, W: Nonlinear Functional Analysis-Fixed Point Theory and its Applications. Yokohama Publishers, Yokohama (2000)

14. Itoh, S, Takahashi, W: The common fixed point theory of single-valued mappings and multi-valued mappings. Pac J Math. 79, 493-508 (1978) 
15. Takahashi, W, Toyoda, M: Weak convergence theorems for nonexpansive mappings and monotone mappings. J Optim Theory Appl. 118, 417-428 (2003). doi:10.1023/A:1025407607560

16. Kurokawa, Y, Takahashi, W: Weak and strong convergence theorems for non-spreading mappings in Hilbert spaces. Nonlinear Anal. 73, 1562-568 (2010). doi:10.1016/..na.2010.04.060

doi:10.1186/1687-1812-2011-51

Cite this article as: Lin et al:: Fixed point theorems for some new nonlinear mappings in Hilbert spaces. Fixed Point Theory and Applications 2011 2011:51.

Submit your manuscript to a SpringerOpen ${ }^{\odot}$ journal and benefit from:

- Convenient online submission

- Rigorous peer review

- Immediate publication on acceptance

- Open access: articles freely available online

- High visibility within the field

- Retaining the copyright to your article

Submit your next manuscript at $\gg$ springeropen.com 